Berkala Ilmu Perpustakaan dan Informasi, Vol. 16, No. 1, Juni 2020, Hal. 32-43

DOI: 10.22146/bip.v16i1.219

ISSN 1693-7740 (Print), ISSN 2477-0361 (Online)

Tersedia online di https://journal.ugm.ac.id/v3/BIP

\title{
Analisis karya tulis ilmiah Pusat Penelitian Geoteknologi LIPI tahun 2010-2018
}

\author{
Didik Prata Wijaya ${ }^{1}$, Abdurrakhman Prasetyadi ${ }^{2}$ \\ ${ }^{1,2}$ Pusat Data dan Dokumentasi Ilmiah, Lembaga Ilmu Pengetahuan Indonesia \\ Jalan Sangkuriang Gedung 40 Komplek LIPI Bandung \\ e-mail:di2kwijaya@gmail.com
}

Naskah diterima: 16 Maret 2020, direvisi: 8 Mei 2020, disetujui: 10 Mei 2020

\begin{abstract}
ABSTRAK
Pendahuluan. Karya tulis ilmiah (KTI) di Puslit Geoteknologi LIPI terus bertumbuh secara kualitas dan kuantitas, maka perlu dilakukan analisis dan kajian terhadap karya ilmiah tersebut untuk mengungkap sejauh mana KTI memberikan kontribusi terhadap Puslit Geoteknologi.

Metode penelitian. Metode penelitian yang digunakan adalah deskriptif dengan pendekatan bibliometrik. Pengumpulan data diperoleh dari laporan tahunan tahun 2010-2018.

Data analisis. Data yang sudah dikumpulkan kemudian dianalisis secara deskriptif menggunakan software Ms.Excel untuk memudahkan pendistribusian dan visualisasi data.

Hasil dan Pembahasan. Hasil dari kajian ini diketahui bahwa KTI yang dipublikasikan oleh peneliti di Puslit Geoteknologi tersebar di berbagai jurnal nasional/internasional, prosiding nasional/internasional, dan buku/bunga rampai. KTI tertinggi yang dipublikasikan adalah prosiding nasional sebanyak 343 judul. Posisi kedua ditempati oleh jurnal internasional sebanyak 182 judul. Ketiga, jurnal nasional sebanyak 104 judul. Terakhir prosiding internasional dengaan 92 judul dan buku sebanyak 67 judul. Bahasa Indonesia paling banyak digunakan yaitu sebanyak 542 artikel dan jenis kelamin penulis laki-laki mendominasi sebanyak 1946 orang. Sementara tahun dimana terdapat satu jenis KTI tertinggi yang dipublikasikan yaitu tahun 2014 dengan 63 judul prosiding nasional.

Kesimpulan dan Saran. Penelitian ini telah mendeskripsikan sebaran KTI Puslit Geoteknologi, dimana KTI prosiding nasional paling dominan dan jurnal internasional paling sedikit salah satunya disebabkan keterbatasannya dana publikasi.
\end{abstract}

Kata kunci: karya tulis ilmiah (KTI); Puslit Geoteknologi; bibliometrik; sebaran

\section{ABSTRACT}

Introduction. Research papers (Karya Tulis Ilmiah - KTI) at Research Center for Geotechnology-LIPI continues to grow in terms of quality and quantity. It is necessary to analyze and study how the research papers contributes the Research Center.

Research methods. The research method used was a descriptive with the bibliometric approach. Data collection was obtained from annual reports from 2010-2018.

Analysis data. The data was analyzed descriptively by using Ms. Excel software to facilitate the distribution and visualization of data.

Results and Discussion. The results of this study showed that KTI published by researchers at the Research Center for Geotechnology were published in various national/international journals, national/international proceedings, and books. The highest number of KTI publication were shown in national proceedings, with 343 titles in total. The second position was publication in international journals with 182 titles. The third position was 104 publication in national journals. The last position was shown in international proceedings with 92 titles and 67 books. Indonesian is the most widely used language in 542 articles and male dominates the authors with 1946 researchers. In terms of year of publication, 2014 was the year with 63 national proceedings. 
Conclusion and recommendations. This research explores the distribution of KTI at Research Center Geotechnology, dominated by KTI which published in national proceeding

Keywords: scientific papers; Research Center for Geotechnology; bibliometrics; distribution

\section{A. PENDAHULUAN}

Karya tulis ilmiah (KTI) merupakan salah satu produk utama aktivitas penelitian ilmiah di samping potensi aplikasi pengetahuan ilmiah yang dihasilkan dalam bentuk teknologi. Oleh karena itu, aktivitas penelitian dapat dipandang sebagai ujung tombak yang bermata dua yang di satu sisi menghasilkan pengetahuan ilmiah (scientific knowledge) mengenai fenomena alam (discovery) sedangkan di sisi lain pengetahuan tersebut dapat memiliki potensi untuk dikembangkan menjadi teknologi yang mampu menghasilkan produk dan atau jasa (goods \& service) (Ansar, 2015).

KTI bermula dari adanya masalah. Untuk dapat memecahkan masalah, peneliti harus memahami asal-muasal masalah itu dengan mencari banyak teori. Teori yang terkumpul disimpulkan dan membentuk sebuah pemahaman baru. Pemahaman baru tersebut pun harus dipadukan dengan data lapangan agar tidak hanya berpandangan sempit. Data lapangan dapat diambil dengan observasi, penyebaran kuesioner, wawancara, dan lainnya. Data yang telah diperoleh lalu dipadukan dengan teori dan menghasilkan simpulan baru. Dari simpulan ini, peneliti harus menarik kaitan antara data dan fakta untuk dapat menemukan solusi. (Kurniadi, 2017).

Ledakan dari informasi jurnal adalah indikator untuk menumbuhkan literatur di setiap bagian pengembangan ilmu. Tumbuh sebagai arus utama untuk menyebarluaskan data, informasi dan pengetahuan, tetapi masih memiliki permasalahan untuk mengukur kuantitas dan kualitas artikel jurnal dari hasil penelitian. Berdasarkan penjelasan di atas, sangat penting untuk memiliki penelitian tunggal untuk mengukur kuantitas dan kualitas artikel jurnal menggunakan metode analisis bibliometrik. (Natakusumah, 2012)

Peneliti yang aktif adalah peneliti yang melaksanakan kegiatan penelitian dengan hasil yang dapat dilihat melalui KTI yang ditulisnya. Para peneliti dapat berbagi informasi atau mengkomunikasikan KTInya dalam berbagai bentuk media, termasuk internet. Komunikasi hasil penelitian terus dilakukan melalui berbagai pendekatan dan media untuk memperoleh masukan dari peneliti atau pakar lain, dengan tujuan agar hasil penelitian tersebut dapat dikembangkan lebih lanjut. Hasil penelitian yang dimaksud dapat berupa temuan baru, seperti paten, desain industri, rahasia dagang, prototipe, konsep kebijakan, dan KTI (Royani dkk, 2013).

Pusat Penelitian Geoteknologi (Puslit Geoteknologi) merupakan salah satu satuan kerja dibawah Kedeputian Ilmu Pengetahuan Kebumian-Lembaga Ilmu Pengetahuan Indonesia (LIPI). Puslit Geoteknologi didirikan pada tanggal 1 Agustus 1963, yang saat itu bernama Lembaga Geologi dan Pertambangan Nasional (LGPN). Salah satu tugas pokok dan fungsi dari Puslit Geoteknologi adalah melaksanakan kegiatan penelitian di bidang geoteknologi. Hasil dari kegiatan penelitian tersebut salah satunya berupa KTI. Umumnya KTI yang dihasilkan Puslit Geoteknologi berupa jurnal dan prosiding yang di terbitkan secara nasional dan internasional, serta buku/bunga rampai.

Geoteknologi merupakan bidang ilmu kebumian yang meneliti geodinamika, geofisika, tanah, bebatuan, bencana alam dan kandungan mineral. Penelitian di Puslit Geoteknologi selama ini telah memberikan sumbangsih yang cukup besar bagi bangsa Indonesia khususnya tentang kebencanaan seperti memetakan daerah-daerah potensi bencana, mengkalkulasi kejadian bencana di masa yang akan datang, dan mitigasi yang harus dilakukan. Selain itu, penelitian geoteknologi juga telah mengidentifikasi ribuan bebatuan asli dari Indonesia.

Sejauh ini KTI Puslit Geoteknologi tidak diketahui penyebaran dan perkembangannya. 
Pada observasi awal penulis terhadap laporan tahunan satuan kerja, belum terdapat statistik sebaran, perkembangan tiap tahun maupun perbandingan jumlah dokumen yang dipublikasikan. Padahal KTI merupakan salah satu output utama dari pusat penelitian.

Penelitian ini perlu dilakukan sebagai upaya mengungkap sejauh mana penyebaran dan perkembangan KTI Puslit Geoteknologi selama 8 (delapan) tahun terakhir. Kebaruan dari penelitian ini yaitu pengukuran bibliometrik pada satu topik KTI bidang Geoteknologi yang ditujukan untuk mengetahui karakteristik sebaran KTI di suatu pusat penelitian. Dimana selama ini belum ada kajian tentang sebaran KTI yang fokus pada satu pusat penelitian Geoteknologi. Pada penelitian sebelumnya, Prasetyadi \& Nugroho (2014) hanya mengkaji mengenai tingkat kolaborasi jurnal bidang kebumian. Kemudian, Himawanto \& Wijayanti (2018) yang membahas analisis sitasi jurnal bidang Geosains di Indonesia dan tidak hanya pada satu pusat penelitian.

Tujuan penelitian ini adalah untuk mengetahui sebaran dan perkembangan KTI, perbandingan bahasa yang digunakan, dan perbandingan penulis KTI berdasarkan jenis kelamin di Puslit Geoteknologi. Hasil dari kajian ini diharapkan dapat memberikan masukan kepada Puslit Geoteknologi mengenai analisis KTI Puslit dari tahun 2010-2018. Sehingga dapat dijadikan bahan pertimbangan dalam menetapkan kebijakan untuk meningkatkan hasil penelitian berupa KTI. Selain itu, diharapkan dapat dijadikan sebagai rujukan atau tambahan literatur bagi yang akan melakukan penelitian, terutama dalam objek kajian yang sama, tetapi dalam konteks yang berbeda.

\section{B. TINJAUAN PUSTAKA}

Pusat Penelitian Geoteknologi LIPI sebelumnya bernama Lembaga Geologi dan Pertambangan Nasional (LGPN) atau dikenal sebagai National Institute of Geology and Mining didirikan pada 1 Agustus 1963, dan dipimpin oleh Prof. Dr. J.A. Katili sebagai Direktur. LGPN berada dibawah naungan
Majelis Ilmu Pengetahuan Indonesia (MIPI) dan Dewan Urusan Riset Nasional (DURENAS) yang kemudian berubah menjadi Lembaga Ilmu Pengetahuan Indonesia dikenal sebagai LIPI.

LGPN didirikan dengan maksud untuk melaksanakan dan menyediakan laboratorium bagi pengembangan ilmu-ilmu dasar dan terapan dalam bidang Geologi, Pertambangan, dan Teknik Perminyakan. Pada awal perkembangannya, lembaga ini aktif bekerja sama dengan Institut Teknologi Bandung (ITB), yang membantu dalam pengembangnannya menuju suatu pusat pendidikan yang kuat dalam bidang Geologi. Kampus Lapangan Karangsambung yang sekarang berada dibawah naungan UPT Balai Informasi Konservasi Karangsambung merupakan salah satu hasil kerja sama dengan ITB. Pendirian kampus lapangan tersebut dimaksudkan sebagai tempat pendidikan dasar para calon ahli geologi.

Fokus awal kegiatan penelitian LGPN pada era tahun 60'an sampai dengan awal 1980 adalah penelitian tektonis kawasan tumbukan lempeng, inventarisasi potensi hidrokarbon, penyusunan konsep pertambangan skala kecil dan konsep pemanfaatan batubara dengan nilai bakar rendah pada tahun 1986, proses reorganisasi dalam lingkungan Lembaga Ilmu Pengertahuan Indonesia LIPI mengubah nama LGPN menjadi Puslitbang Geoteknologi LIPI atau Pusat Penelitian dan Pengembangan Geoteknologi (P3G LIPI). Perubahan nama dan struktur organisasi melalui reorganisasi kelembagaan dimaksudkan untuk revitalisasi lembaga menghadapi dinamika perubahan baik perubahan kondisi eksternal maupun internal. Pada masa itu, P3G LIPI mendirikan Laboratorium Penginderaan jauh pada 1986 yang kemudian sekarang menjadi standar dalam kegiatan penelitian. SK Kepala Lembaga Ilmu Pengetahuan Indonesia (LIPI) No. 1151/M/2001 tahun 2001 menandai era baru dimana Pusat Penelitian dan Pengembangan Geoteknologi (P3G LIPI) berubah nama menjadi Pusat Penelitian Geoteknologi LIPI atau P2G LIPI dibawah Kedeputian Bidang Ilmu Pengetahuan Kebumiaan LIPI.

Penelitian yang aktif adalah penelitian yang melaksanakan kegiatan penelitian dengan hasil 
yang dapat dilihat melalui KTI yang ditulisnya. Para peneliti dapat berbagi informasi atau mengkomunikasikan KTI nya dalam berbagai bentuk media, termasuk internet. Komunikasi hasil penelitian terus dilakukan melalui berbagai pendekatan dan media untuk memperoleh masukan dari peneliti atau pakar lain, dengan tujuan agar hasil penelitian tersebut dapat dikembangkan lebih lanjut. Hasil penelitian yang dimaksud dapat berupa temuan baru, seperti paten, desain industri, rahasia dagang, prototipe, konsep kebijakan, dan KTI (Royani, 2013).

Menurut Soemarno (2010) bahwa peneliti terutama yang bernaung di bawah lembaga penelitian pemerintah, dituntut menulis dan mempublikasikan hasil penelitiannya sebagai bentuk pertanggungjawaban atas penggunaan dana dan fasilitas penelitian agar masyarakat mengetahui dan memanfaatkan hasil penelitian tersebut. Selanjutnya Wilis (2015) mengungkapkan peneliti dituntut membuat karya tulis ilmiah (KTI) sebagai salah satu persyaratan bagi jabatan fungsionalnya. Peneliti yang tidak mempublikasi KTI akan mengalami pemutusan jabatan fungsional. Hal serupa disampaikan oleh Sutardji (2017) bahwa kemampuan menyusun karya tulis ilmiah (KTI) sangat diperlukan terutama bagi pejabat fungsional dalam meniti karier untuk mencapai ke jenjang yang lebih tinggi. Sebagai pemegang jabatan fungsional dipersyaratkan menghasilkan karya tulis ilmiah untuk kenaikan jenjang atau pemeliharaan jenjang fungsional.

Karya ilmiah adalah suatu karya yang memuat dan mengkaji suatu masalah tertentu dengan menggunakan kaidah-kaidah keilmuan. Adapun, yang dimaksud dengan kaidah-kaidah keilmuan adalah bahwa karya ilmiah menggunakan metode ilmiah di dalam membahas permasalahan, menyajikan kajiannya menggunakan bahasa baku dan tata tulis ilmiah, serta menggunakan prinsip-prinsip keilmuan yang lain seperti: bersifat objektif, logis, empiris (berdasarkan fakta), sistematis, lugas, jelas, dan konsisten (Rosmiati, 2017).

KTI yang dihasilkan Pusat Penelitian Geoteknologi adalah berupa jurnal, prosiding, serta buku. Menurut Suryoputro (2012) jurnal ilmiah adalah sebuah publikasi yang dipublikasikan secara berkala oleh suatu organisasi profesi atau institusi akademik yang memuat artikel-artikel yang merupakan produk pemikiran ilmiah secara empiris (artikel hasil penelitian) maupun secara logis (artikel hasil pemikiran) dalam bidang ilmu tertentu. Isi dari jurnal ilmiah adalah artikel ilmiah (research articles) yakni tulisan yang berisi laporan sistematis mengenai hasil kajian atau penelitian yang disajikan bagi masyarakat ilmiah tertentu, yang merupakan audiens khusus dengan tujuan menyampaikan hasil kajian dan kontribusi penulis artikel kepada mereka untuk dipikirkan, dikaji kembali, dan diperdebatkan, baik secara lisan maupun secara tertulis. Menurut Kamus Besar Bahasa Indonesia (2019) disebutkan bahwa prosiding adalah kumpulan makalah seminar yang telah dibukukan. Menurut Kurniasih (2014) buku adalah buah pikiran yang berisi ilmu pengetahuan hasil analisis terhadap kurikulum secara tertulis. Buku disusun menggunakan Bahasa sederhana, menarik, dan dilengkapi gambar serta daftar pustaka.

Pada dasarnya, seseorang yang telah berhasil menyusun suatu KTI adalah orang yang telah menempuh sebuah "jalan" yang cukup panjang. Jalan tersebut mencakup kegiatankegiatan:

1. Penentuan tema,

2. Pemilihan dan pengumpulan bahan,

3. Pengorganisasian bahan,

4. Aktifitas berpikir,

5. Aktifitas menerapkan pengetahuan metodelogis,

6. Aktifitas penuangan hasil pemikiran kedalam bentuk tulisan yang antara lain, mencakup pemilihan kalimat, suku kata, tanda baca, aturan pengutipan, dan seterusnya, serta

7. Aktifitas pemeriksaan ulang. Dengan demikian, karya tulis ilmiah tidak lahir tanpa proses dan tanpa norma (Alauddin, 2013).

Pengembangan ilmu pengetahuan seringkali berkaitan dengan produktivitas ilmiah dan kemampuan menghasilkan publikasi ilmiah seseorang (Franceschet, \& Costantini, 2011). Publikasi dapat diukur melalui indikator 
bibliometrik (Piro, 2011). Indikator ini dapat diproduksi dengan metode bibliometrik. Metode ini dapat memecahkan masalah penting dalam publikasi ilmiah, seperti, bagaimana mengukur distribusi artikel, klasifikasi kategori artikel, distribusi subjek artikel, pola kepengarangan dan distribusi kontribusi institusi. Penelitian yang dilakukan oleh Thanuskodi (2010) membahas analisis serupa dengan mengkaji distribusi jumlah artikel, pola kepenulisan, distribusi subjek artikel, dan bentuk dokumen.

Bibliometrik merupakan penerapan metode matematika dan statistika untuk menganalisis jurnal ilmiah dan bentuk-bentuk komunikasi tertulis lainnya (Natakusumah, 2014; Himawanto, Setiawan, \& Sari, 2015). Bibliometrika dapat digunakan sebagai metode dalam mengkaji bidang informasi yang bersifat deskriptif, misalnya yang berkaitan dengan kepenulisan/kepengarangan seperti mengukur produktifitas penulis, kolaborasi kepenulisan dan mengevaluasi kepenulisan seperti mengkaji penggunaan literatur melalui analisis sitiran dan lain-lain. Kajian bibliometrika ini menggunakan statistik untuk mengkuantifikasi dokumen (Rahayu, \& Saleh, 2017).

\section{METODE PENELITIAN}

Metode penelitian yang digunakan yaitu deskriptif dengan pendekatan analisis bibliometrik. Penelitian ini dilakukan terhadap KTI Pusat Penelitian Geoteknologi LIPI yang terbit tahun 2010-2018 (terbitan selama delapan tahun). Dari hasil observasi awal diketahui bahwa perincian KTI yang dipublikasikan diantaranya yaitu jurnal internasional, jurnal nasional, prosiding internasional, prosiding nasional, dan buku/bunga rampai. Data KTI Pusat Penelitian Geoteknologi didapatkan melalui laporan tahunan Pusat Penelitian Geoteknologi tahun 2010, 2011, 2012, 2013, 2014, 2015, 2016, 2017, dan 2018 diunduh secara online melalui alamat http://geotek.lipi.go.id/?page_id=8265.

Data dari KTI tersebut kemudian dianalisis secara deskriptif yang diolah dengan menggunakan software Microsoft Excel untuk memudahkan pendistribusian data dan tampilan dalam format tabel dan grafik. Selanjutnya pengolahan data tersebut digunakan untuk mengetahui jumlah KTI Pusat Penelitian Geoteknologi LIPI tahun 2010-2018 yang dipublikasikan pada jurnal internasional, jumlah KTI Pusat Penelitian Geoteknologi LIPI tahun 2010-2018 yang dipublikasikan pada jurnal nasional, jumlah KTI Pusat Penelitian Geoteknologi LIPI tahun 2010-2018 yang dipublikasikan pada prosiding internasional, jumlah KTI Pusat Penelitian Geoteknologi LIPI tahun 2010-2018 yang dipublikasikan pada prosiding nasional, jumlah KTI Pusat Penelitian Geoteknologi LIPI tahun 2010-2018 yang dipublikasikan pada buku/bunga rampai, jumlah KTI Pusat Penelitian Geoteknologi LIPI tahun 2010-2018 berdasarkan bahasa dari setiap artikel, serta jumlah penulis KTI Pusat Penelitian Geoteknologi LIPI tahun 2010-2018 berdasarkan jenis kelamin.

Data yang diperoleh selanjutnya dikelompokan ke dalam kategori, yaitu: jenis dan jumlah terbitan, bidang, media, jumlah pengarang dan penerbit.

Data dihitung dengan menggunakan rumus:

$$
p=\frac{f}{N} \times 100 \%
$$

$\mathrm{P}=$ persentase

$\mathrm{F}=$ frekuensi jenis terbitan/bidang/media/ jumlah pengarang/penerbit.

$\mathrm{N}=$ jumlah total jenis terbitan/bidang/ media/jumlah pengarang/penerbit (Rahayu, 2014)

\section{HASIL DAN PEMBAHASAN Hasil}

\section{Sebaran dan Perkembangan KTI}

Berdasarkan hasil analisis dapat diketahui bahwa sebaran dan perkembangan KTI di Puslit Geoteknologi cukup bervariasi dan beragam setiap tahunnya, ada yang dipublikasikan di prosiding nasional hingga jurnal internasional. Sebaran dan perkembangan KTI pada Gambar 1 didominasi oleh prosiding nasional hingga 343 judul dan jumlah tertinggi pada satu tahun sebanyak 63 judul prosiding nasional di tahun 2014. Berikut pembahasan lebih lengkap dari hasil penelitian ini. 
a) KTI dalam bentuk jurnal internasional tahun 2010-2018

Data pada Tabel 1 dapat dilihat bahwa karya tulis ilmiah yang di terbitkan pada jurnal internasional tahun 2010 sebanyak 8 judul atau $7.69 \%$, tahun 2011 sebanyak 12 judul atau 11.54 $\%$, tahun 2012 sebanyak 10 judul atau $9.62 \%$, tahun 2013 sebanyak 6 judul atau $5.77 \%$, tahun 2014 sebanyak 6 judul atau $5.77 \%$, tahun 2015 sebanyak 10 judul atau $9.62 \%$, tahun 2016 sebanyak 20 judul atau $19.23 \%$, tahun 2017 sebanyak 13 judul atau $12.50 \%$, dan tahun 2018 sebanyak 19 judul atau $18.27 \%$. Dapat disimpulkan bahwa karya tulis ilmiah tertinggi yang di terbitkan pada jurnal internasional adalah pada tahun 2016 yaitu sebanyak 20 judul atau $19.23 \%$. Sedangkan karya tulis ilmiah terendah yang dipublikasikan pada jurnal internasional adalah pada tahun 2013 dan 2014 sebanyak 6 judul atau $5.77 \%$.

b) KTI dalam bentuk jurnal nasional tahun 2010-2018

Data pada Tabel 1 dapat dilihat bahwa karya tulis ilmiah yang di terbitkan pada jurnal nasional tahun 2010 sebanyak 15 judul atau 8.24 $\%$, tahun 2011 sebanyak 17 judul atau $9.34 \%$, tahun 2012 sebanyak 33 judul atau $18.13 \%$, tahun 2013 sebanyak 23 judul atau $12.64 \%$, tahun 2014 sebanyak 22 judul atau $12.09 \%$, tahun 2015 sebanyak 13 judul atau $7.14 \%$, tahun 2016 sebanyak 15 judul atau $8.24 \%$, tahun 2017 sebanyak 24 judul atau $13.19 \%$, dan tahun 2018 sebanyak 20 judul atau $10.99 \%$. Dapat disimpulkan bahwa karya tulis ilmiah tertinggi yang di terbitkan pada jurnal nasional adalah pada tahun 2012 yaitu sebanyak 33 judul atau $18.13 \%$. Sedangkan karya tulis ilmiah terendah yang dipublikasikan pada jurnal nasional adalah pada tahun 2015 sebanyak 13 judul atau $7.14 \%$.

c) KTI dalam bentuk prosiding internasional tahun 2010-2018

Data pada Tabel 2 dapat dilihat bahwa karya tulis ilmiah yang di terbitkan pada prosiding international tahun 2010 sebanyak 6 judul atau $6.59 \%$, tahun 2011 sebanyak 5 judul atau $5.49 \%$, tahun 2012 sebanyak 4 judul atau
$4.40 \%$, tahun 2013 sebanyak 4 judul atau 4.40 $\%$, tahun 2014 sebanyak 9 judul atau $9.89 \%$, tahun 2015 sebanyak 12 judul atau $13.19 \%$, tahun 2016 sebanyak 5 judul atau $5.49 \%$, tahun 2017 sebanyak 41 judul atau $45.05 \%$, dan tahun 2018 sebanyak 5 judul atau $5.49 \%$. Dapat disimpulkan bahwa karya tulis ilmiah tertinggi yang di terbitkan pada prosiding internasional adalah pada tahun 2017 yaitu sebanyak 41 judul atau $44.57 \%$. Sedangkan karya tulis ilmiah terendah yang dipublikasikan pada prosiding internasional adalah pada tahun 2012 dan 2013 sebanyak 4 judul atau $4.40 \%$.

d) KTI dalam bentuk prosiding nasional tahun 2010-2018

Data pada Tabel 2 dapat dilihat bahwa karya tulis ilmiah yang di terbitkan pada prosiding nasional tahun 2010 sebanyak 47 judul atau $13.70 \%$, tahun 2011 sebanyak 53 judul atau $15.45 \%$, tahun 2012 sebanyak 51 judul atau $14.87 \%$, tahun 2013 sebanyak 52 judul atau $15.16 \%$, tahun 2014 sebanyak 63 judul atau $18.37 \%$, tahun 2015 sebanyak 18 judul atau $5.25 \%$, tahun 2016 sebanyak 48 judul atau $13.99 \%$, tahun 2017 sebanyak 9 judul atau 2.62 $\%$, dan tahun 2018 sebanyak 2 judul atau $0.58 \%$. Dapat disimpulkan bahwa karya tulis ilmiah tertinggi yang di terbitkan pada prosiding nasional adalah pada tahun 2014 yaitu sebanyak 63 judul atau $18.37 \%$. Sedangkan karya tulis ilmiah terendah yang dipublikasikan pada prosiding nasional adalah pada tahun 2018 sebanyak 2 judul atau $0.58 \%$.

e) KTI dalam bentuk Buku/Bunga Rampai Tahun 2010-2018

Data pada Tabel 3 dapat dilihat bahwa karya tulis ilmiah yang di terbitkan dalam bentuk buku tahun 2010 sebanyak 0 judul atau $0.00 \%$, tahun 2011 sebanyak 10 judul atau $14.93 \%$, tahun 2012 sebanyak 8 judul atau $11.94 \%$, tahun 2013 sebanyak 11 judul atau $16.42 \%$, tahun 2014 sebanyak 20 judul atau $29.85 \%$, tahun 2015 sebanyak 7 judul atau $10.45 \%$, tahun 2016 sebanyak 6 judul atau $8.96 \%$, tahun 2017 sebanyak 4 judul atau $5.97 \%$, dan tahun 2018 sebanyak 1 judul atau $1.49 \%$. Dapat disimpulkan bahwa karya tulis ilmiah tertinggi 
yang di terbitkan dalam bentuk buku adalah pada tahun 2014 yaitu sebanyak 20 judul atau $29.85 \%$. Sedangkan karya tulis ilmiah terendah yang dipublikasikan dalam bentuk buku adalah pada tahun 2010 sebanyak 0 judul atau $0.00 \%$.

\section{Bahasa KTI}

Data pada Tabel 4 dapat dilihat bahwa tahun 2010 KTI berbahasa Indonesia sebanyak 56 artikel atau 10,33\% dan berbahasa Inggris sebanyak 20 artikel atau 8,33\%. Tahun 2011 KTI berbahasa Indonesia sebanyak 71 artikel atau 13,10\% dan berbahasa Inggris sebanyak 26 artikel atau 10,83\%. Tahun 2012 KTI berbahasa Indonesia sebanyak 81 artikel atau 14,94\% dan berbahasa Inggris sebanyak 21 artikel atau 8,75\%. Tahun 2013 KTI berbahasa Indonesia sebanyak 81 artikel atau $14,94 \%$ dan berbahasa Inggris sebanyak 15 artikel atau 6,25\%. Tahun 2014 KTI berbahasa Indonesia sebanyak 101 artikel atau 18,63\% dan berbahasa Inggris sebanyak 19 artikel atau 7,92\%. Tahun 2015 KTI berbahasa Indonesia sebanyak 29 artikel atau 5,35\% dan berbahasa Inggris sebanyak 31 artikel atau 12,92\%. Tahun 2016 KTI berbahasa Indonesia sebanyak 68 artikel atau $12,55 \%$ dan berbahasa Inggris sebanyak 25 artikel atau 10,42\%. Tahun 2017 KTI berbahasa Indonesia sebanyak 36 artikel atau $6,64 \%$ dan berbahasa Inggris sebanyak 55 artikel atau 22,92\%. Tahun 2018 KTI berbahasa Indonesia sebanyak 19 artikel atau 3,51\% dan berbahasa Inggris sebanyak 28 artikel atau $11,67 \%$.

Dengan demikian dari penjelasan diatas dapat diketahui bahwa jumlah KTI tertinggi berbahasa Indonesia terdapat pada tahun 2014 sebanyak 101 artikel $(18,63 \%)$ dan KTI terendah pada tahun 2018 sebanyak 19 artikel $(3,51 \%)$. KTI tertinggi berbahasa Inggris terdapat pada tahun 2017 sebanyak 55 artikel $(22,92 \%)$ dan KTI terendah pada tahun 2013 sebanyak 15 artikel (6,25\%). Secara total KTI tertinggi adalah artikel dengan berbahasa Indonesia yaitu sebanyak 542 artikel, dan terendah adalah artikel dengan berbahasa Inggris yaitu sebanyak 240 artikel.

\section{Penulis KTI Berdasarkan Jenis Kelamin}

Data pada Tabel 5 dapat dilihat bahwa penulis KTI pada tahun 2010 dengan jenis kelamin laki-laki adalah sebanyak 166 orang atau $8,53 \%$ dan perempuan sebanyak 43 orang atau 7,93\%. Penulis KTI pada tahun 2011 dengan jenis kelamin laki-laki adalah sebanyak 240 orang atau $12,33 \%$ dan perempuan sebanyak 55 orang atau $10,15 \%$. Penulis KTI laki-laki pada tahun 2012 adalah sebanyak 248 orang atau $12,74 \%$ dan perempuan sebanyak 77 orang atau 14,21\%. Penulis KTI laki-laki pada tahun 2013 adalah sebanyak 231 orang atau $11,87 \%$ dan perempuan sebanyak 77 orang atau $14,21 \%$. Penulis KTI laki-laki pada tahun 2014 adalah sebanyak 333 orang atau $17,11 \%$ dan perempuan sebanyak 76 orang atau $14,02 \%$. Penulis KTI laki-laki pada tahun 2015 adalah sebanyak 141 orang atau 7,25\% dan perempuan sebanyak 38 orang atau 7,01\%. Penulis KTI laki-laki pada tahun 2016 adalah sebanyak 252 orang atau $12,95 \%$ dan perempuan sebanyak 84 orang atau $15,50 \%$. Penulis KTI laki-laki pada tahun 2017 adalah sebanyak 176 orang atau 9,04\% dan perempuan sebanyak 51 orang atau 9,41\%. Penulis KTI laki-laki pada tahun 2018 adalah sebanyak 159 orang atau $8,17 \%$ dan perempuan sebanyak 41 orang atau 7,56\%.

Dengan demikian dari penjelasan diatas dapat diketahui bahwa jumlah penulis KTI tertinggi dengan jenis kelamin laki-laki terdapat pada tahun 2014 sebanyak 333 orang $(17,11 \%)$ dan penulis KTI terendah dengan jenis kelamin laki-laki terdapat pada tahun 2015 sebanyak 141 orang $(7,25 \%)$. Penulis KTI tertinggi dengan jenis kelamin perempuan terdapat pada tahun 2016 sebanyak 84 orang $(15,50 \%)$ dan penulis KTI terendah dengan jenis kelamin perempuan terdapat pada tahun 2015 sebanyak 38 orang $(7,01 \%)$. Secara total penulis KTI tertinggi adalah penulis laki-laki yaitu sebanyak 1946 orang, dan terendah adalah penulis perempuan yaitu sebanyak 542 orang. 


\section{Pembahasan}

Berdasarkan hasil penelitian di atas, dapat diungkap bahwa tulisan KTI jenis prosiding mendominasi dibandingkan jenis publikasi lainnya di Puslit Geoteknologi. Hasil penelitian ini juga menjadi temuan baru karena pada penelitian-penelitian sebelumnya jenis publikasi terbanyak yang dihasilkan di lembaga penelitian yaitu berupa jurnal dan sitasinya dianggap melampaui jenis publikasi lainnya (Royani dkk, 2013; Abeyrathne, 2015; Bullis, 2013). Hal ini menjadi penting bagi pemangku kebijakan di Puslit Geoteknologi untuk memprioritaskan anggaran untuk biaya seminar, konferensi dan sejenisnya.

Dari hasil di atas juga diungkapkan bahwa jurnal internasional paling sedikit sebaran dan perkembangannya di Puslit Geoteknologi. Mungkin ada beberapa faktor yang menghambat penulis menerbitkan KTI di jurnal internasional seperti keterbatasan dana, keterbatasan waktu, kesulitan mencari referensi karena tertutup dan berbayar, proses publikasi relatif lama, keterbatasan kemampuan bahasa asing, keterbatasan kemampuan penggunaan alat bantu software, dan keterbatasan informasi jurnal internasional bereputasi (Purwanto dkk, 2020). Oleh karena itu, jurnal akreditasi nasional dan prosiding nasional menjadi opsi pertimbangan untuk mempublikasikan KTI. Himawanto \& Handajani (2017) juga mengemukakan jika periset lokal menyadari, sebenarnya mereka ikut andil terhadap rendahnya publikasi tajuk kebumian bertaraf internasional.

Selain itu, bahasa yang paling banyak digunakan adalah bahasa Indonesia sebanyak 69,3\%. Hal ini juga membuktikan bahwa peneliti di Puslit Geoteknologi meminati KTInya dipublikasikan pada jenis publikasi berbahasa Indonesia. Tentunya keputusan peneliti atau penulis mempublikasikan KTI berbahasa Indonesia dan nasional ada beberapa faktor lain selain hambatan di atas. Diantaranya yaitu karena ruang lingkup penelitian yang hanya mencakup tentang penelitian lokal di Indonesia dan tidak mesti dipublikasikan secara internasional, target publikasi hanya publikasi nasional, dan penelitian yang berupa produk paten nasional.

Terakhir diketahui bahwa jenis kelamin yang paling banyak mempublikasikan KTI di Puslit Geoteknologi sepanjang tahun 2010-2018 yaitu laki-laki sebanyak 78,2\%. Ini mengindikasikan bahwa penulis laki-laki lebih produktif atau memang lebih banyak jumlahnya ketimbang perempuan di satuan kerjanya. Seperti diketahui bahwa bidang Geoteknologi merupakan penelitian lapangan dengan medan yang cukup sulit seperti pegunungan, pedalaman hutan, pesisir laut dan sebagainya. Jadi tidak banyak peneliti perempuan yang berminat di bidang ilmu kebumian ini.

Dari sisi bahasa dan jenis kelamin penulis KTI kajian ini sejalan dengan Himawanto (2015) dalam kajian bibliometrik terhadap artikel bidang teknologi minyak gas bumi di Indonesia. Bahwa sebagian besar rekaman kegiatan riset ditulis ke dalam bahasa Indonesia dan capaian artikel yang dihasilkan penulis lakilaki sebanyak $75,47 \%$ lebih tinggi dibandingkan penulis perempuan yang hanya $24,53 \%$.

\section{E. KESIMPULAN \\ Kesimpulan}

KTI yang dipublikasikan oleh peneliti di Puslit Geoteknologi tersebar di berbagai jurnal nasional/internasional, prosiding nasional/internasional, dan buku/bunga rampai. KTI tertinggi yang dipublikasikan adalah prosiding nasional yaitu sebanyak 343 judul. Posisi kedua ditempati oleh jurnal internasional sebanyak 182 judul. Ketiga, jurnal nasional sebanyak 104 judul. Terakhir prosiding internasional dengan 92 judul dan buku sebanyak 67 judul. Sementara jenis KTI tertinggi yang dipublikasikan yaitu prosiding nasional pada tahun 2014 sebanyak 63 judul. Bahasa Indonesia paling banyak digunakan yaitu sebanyak 542 artikel dan terendah adalah artikel dengan berbahasa Inggris yaitu sebanyak 240 artikel. Terakhir, jenis kelamin penulis KTI tertinggi adalah penulis laki-laki yaitu sebanyak 1946 orang, dan terendah adalah penulis perempuan yaitu sebanyak 542 orang.

Penelitian ini mengungkapkan bahwa KTI jenis prosiding mendominasi dibandingkan jenis publikasi lainnya di Puslit Geoteknologi, 
terutama prosiding nasional. Hal ini menjadi temuan baru dimana biasanya jenis publikasi terbanyak yang dihasilkan oleh lembaga penelitian yaitu berupa jurnal. Pernyataan tersebut didukung dengan hasil penelitian di atas bahwa sebaran publikasi jurnal internasional yang paling sedikit mungkin dikarenakan beberapa hambatan seperti keterbatasan dana, kesulitan mencari referensi, dan sebagainya.

\section{Saran}

Berdasarkan pada kesimpulan yang diperoleh maka Puslit Geoteknologi sebaiknya dapat melakukan pertimbangan untuk pengembangan indeks penulis dan peta sebaran KTI agar dapat terdokumentasikan dengan baik. Selain itu, agar terwujud peningkatan produk riset kegeologian bertaraf global, peneliti Puslit Geoteknologi sebaiknya mengubah ideologi dengan membatasi porsi di terbitan berkala ilmiah nasional.

\section{DAFTAR PUSTAKA}

Abeyrathne, D.K. (2015). Citation analysis of dissertations for collection development. Collection Building, 34(2), 30-40.

Ansar. (2015). Kajian sebaran dan perkembangan karya tulis ilmiah peneliti balai penelitian dan pengembangan budidaya air payau yang terindeks pada pangkalan data winisis. J. Pari, 1(1), 17-26.

Bullis, D.R., \& Irving, R.D. (2013). Journals supporting terrorism research: Identification and investigation into their impact on the social sciences. College \& Research Libraries, 74(2), 119-129.

Franceschet, M., \& Costantini, A. (2011). The first italian research assessment exercise - a bibliometric perspective. Journal of Informetrics, 5(2), 275-291.

Himawanto. (2015). Kajian bibliometrik terhadap artikel bidang teknologi minyak gas bumi di Indonesia. BACA: Jurnal Dokumentasi dan Informai 36(1): 11-30.

Himawanto, \& Handajani, T. (2017). Senarai penelitian kegeologian 2011-2016: perspektif bibliometrik indonesian journal on geoscience. Media Pustakawan, 24(4), 45-53.
Himawanto, Setiawan, H., \& Sari, L.M.H. (2015). Karakteristik terbitan berkala bidang perpustakaan di Indonesia.Visi Pustaka, 17(2), 72-85.

Himawanto, \& Wijayanti, L. (2018). Pengembangan koleksi untuk program internasionalisasi jurnal bidang geosains di Indonesia: analisis sitasi. Khizanah alHikmah : Jurnal Ilmu Perpustakaan, Informasi, dan Kearsipan, 6(1), 55-66.

Kurniadi, Fajar. (2017). Penulisan karya tulis ilmiah mahasiswa dengan media aplikasi pengolah kata. AKSIS: Jurnal Pendidikan dan Bahasa Sastra Indonesia, 1(2), 267277.

Kurniasih, I., \& Sani, B. (2014). Buku teks pelajaran sesuai dengan kurikulum 2013. Surabaya: Kata Pena.

Natakusumah, E.K. (2012, November). Peranan bibliometrik untuk mengukur kualitas hasil penelitian ilmiah (the role of bibliometrics to measure the quality of sicentific research result). Makalah dipersentasikan pada Seminar Nasional Ilmu Pengetahuan Teknik: Teknologi untuk Mendukung Pembangunan Nasional, Bandung, Jawa Barat.

Natakusumah, E.K. (2014). Penentuan kolaborasi penelitian dan distribusi pengarang pada Jurnal Teknologi Indonesia. BACA: Jurnal Dokumentasi dan Informasi, 35(1), 15-24.

Piro, F.N. (2011). Comparing research at nordic universities using bibliometric indicators. Oslo: Nordforsk.

Prasetyadi, A.R., \& Nugroho, D.W.A. (2014). Kolaborasi kepakaran peneliti pada jurnal ilmiah LIPI bidang informatika dan kebumian. VISI PUSTAKA, 16(1), 5-13.

Purwanto, A., Pramono, R., Bernarto, I., Asbari, M., Priyono, B.S., Ong, F., Kusumaningsih, W., Mustikasiwi, A., Prameswari, M., Wijayanti, L.M., \& Hyun, C.C. 2020. Peluang dan hambatan publikasi artikel pada jurnal internasional bereputasi: studi eksploratori pada mahasiswa doktoral di sebuah perguruan tinggi swasta di Jakarta. EDUMASPUL: Jurnal Pendidikan, 4(1), 219-228. 
Pusat Penelitian Geoteknologi. (2019). Laporan Tahunan Geoteknologi. 21 Januari, 2020.

http://geotek.lipi.go.id/?page_id=8265

Rahayu, N.R. (2014). Analisis publikasi kebun raya bogor tahun 1994 -2012. Jurnal Baca, 35(1), 53-72.

Rahayu, S., \& Saleh, A.R. (2017). Studi bibliometrik dan sebaran topik penelitian pada jurnal hayati terbitan 2012-2016. Pustakaloka, 9(2), 201-218.

Rosmiati, A. (2017). Dasar-dasar penulisan karya ilmiah. Surakarta: ISI Press.

Royani, Y., Bachtar, M.A., Tambunan, K., Tupan, \& Sugiharto (2013). Pemetaan karya tulis ilmiah LPNK: studi kasus LIPI dan BPPT (2004-2008). Baca: Jurnal Dokumentasi dan Informasi, 34(1), 1-28.

Sumarno. 2010. Peningkatan kinerja peneliti dan mutu publikasi ilmiah pada unit kerja penelitian. hlm. 51-66. Dalam Hermanto dan Sunihardi (Ed.). Prosiding Rapat Kerja 2010: Reformasi Birokrasi dan Diseminasi Hasil Penelitian Tanaman Pangan. Bogor: Puslitbang Tanaman Pangan.
Suryoputro, G., Riadi, S., \& Syaban, A. (2012). Menulis artikel untuk jurnal ilmiah. Jakarta: Uhamka Press.

Sutardji \& Maulidyah, S.S. (2017). Analisis bibliometrika terhadap karya tulis ilmiah: studi kasus di Balai Penelitian Tanaman Aneka Kacang dan Umbi. Media Pustakawan, 24(2), 52-58.

Thanuskodi, S. (2010). Journal of social sciences: a bibliometric study. Journal of Social Science, 24(2): 77-80.

Universitas Islam Negeri Alauddin. (2013). Pedoman Penulian Karya Tulis Ilmiah. Makassar: UIN Alauddin Press.

Wilis, J. (2015). Keterpakaian dan relevansi jurnal penelitian pertanian tanaman pangan sebagai rujukan karya tulis peneliti pada jurnal ilmiah terakreditasi. Jurnal Perpustakaan Pertanian, 24(2), 78-84. DOI: $\quad$ http://dx.doi.org/10.21082/jpp. v24n2.2015.p78-84 


\section{DAFTAR GAMBAR}

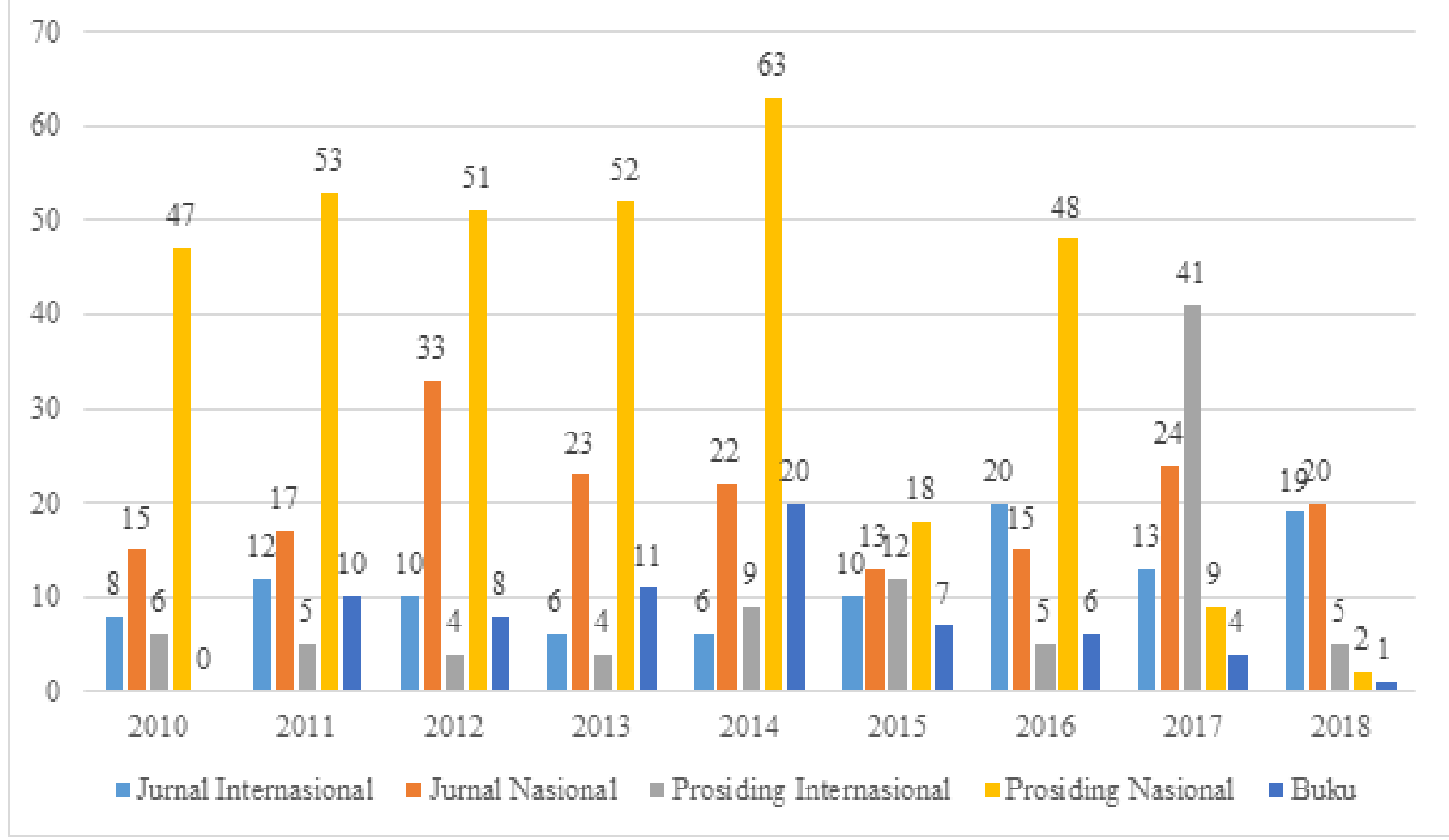

Gambar 1. Grafik Perkembangan KTI Tahun 2010 - 2018

\section{DAFTAR TABEL}

Tabel 1. Karya Tulis Ilmiah Jurnal Internasional \& Nasional Tahun 2010-2018

\begin{tabular}{ccccc}
\hline Tahun & $\begin{array}{c}\text { Jurnal } \\
\text { Internasional }\end{array}$ & $\mathbf{\%}$ & $\begin{array}{c}\text { Jurnal } \\
\text { Nasional }\end{array}$ & $\mathbf{\%}$ \\
\hline 2010 & 8 & 7.69 & 15 & 8.24 \\
2011 & 12 & 11.54 & 17 & 9.34 \\
2012 & 10 & 9.62 & 33 & 18.13 \\
2013 & 6 & 5.77 & 23 & 12.64 \\
2014 & 6 & 5.77 & 22 & 12.09 \\
2015 & 10 & 9.62 & 13 & 7.14 \\
2016 & 20 & 19.23 & 15 & 8.24 \\
2017 & 13 & 12.50 & 24 & 13.19 \\
2018 & 19 & 18.27 & 20 & 10.99 \\
Jumlah & $\mathbf{1 0 4}$ & $\mathbf{1 0 0}$ & $\mathbf{1 8 2}$ & $\mathbf{1 0 0}$ \\
\hline
\end{tabular}

Sumber: Data primer diolah 2019 
Tabel 2. Karya Tulis Ilmiah Prosiding Internasional Tahun 2010-2018

\begin{tabular}{ccccc}
\hline Tahun & $\begin{array}{c}\text { Prosiding } \\
\text { Internasional }\end{array}$ & $\mathbf{\%}$ & $\begin{array}{c}\text { Prosiding } \\
\text { Nasional }\end{array}$ & \% \\
\hline 2010 & 6 & 6,59 & 47 & 13.70 \\
2011 & 5 & 5,49 & 53 & 15.45 \\
2012 & 4 & 4,40 & 51 & 14.87 \\
2013 & 4 & 4,40 & 52 & 15.16 \\
2014 & 9 & 9,89 & 63 & 18.37 \\
2015 & 12 & 13,19 & 18 & 5.25 \\
2016 & 5 & 5,49 & 48 & 13.99 \\
2017 & 41 & 45,05 & 9 & 2.62 \\
2018 & 5 & 5,49 & 2 & 0.58 \\
Jumlah & $\mathbf{9 2}$ & $\mathbf{1 0 0}$ & $\mathbf{3 4 3}$ & $\mathbf{1 0 0}$ \\
\hline
\end{tabular}

Sumber: Data primer diolah 2019

Tabel 3. Karya Tulis Ilmiah Buku/Bunga Rampai Tahun 2010-2018

\begin{tabular}{ccc}
\hline Tahun & Jumlah KTI & \% \\
\hline 2010 & 0 & 0.00 \\
2011 & 10 & 14.93 \\
2012 & 8 & 11.94 \\
2013 & 11 & 16.42 \\
2014 & 20 & 29.85 \\
2015 & 7 & 10.45 \\
2016 & 6 & 8.96 \\
2017 & 4 & 5.97 \\
2018 & 1 & 1.49 \\
Jumlah & $\mathbf{6 7}$ & $\mathbf{1 0 0}$ \\
\hline
\end{tabular}

Sumber: Data primer diolah 2019

Tabel 4. Bahasa dari setiap artikel di KTI tahun 2010-2018

\begin{tabular}{ccccc}
\hline Tahun & Indonesia & $\mathbf{\%}$ & Inggris & \% \\
\hline 2010 & 56 & 10,33 & 20 & 8,33 \\
2011 & 71 & 13,10 & 26 & 10,83 \\
2012 & 81 & 14,94 & 21 & 8,75 \\
2013 & 81 & 14,94 & 15 & 6,25 \\
2014 & 101 & 18,63 & 19 & 7,92 \\
2015 & 29 & 5,35 & 31 & 12,92 \\
2016 & 68 & 12,55 & 25 & 10,42 \\
2017 & 36 & 6,64 & 55 & 22,92 \\
2018 & 19 & 3,51 & 28 & 11,67 \\
Jumlah & $\mathbf{5 4 2}$ & $\mathbf{1 0 0}$ & $\mathbf{2 4 0}$ & $\mathbf{1 0 0}$ \\
\hline
\end{tabular}

Sumber: Data primer diolah 2019

Tabel 5. Penulis KTI berdasarkan jenis kelamin tahun 2010-2018

\begin{tabular}{ccccc}
\hline Tahun & Laki-laki & $\mathbf{\%}$ & Perempuan & \% \\
\hline 2010 & 166 & 8,53 & 43 & 7,93 \\
2011 & 240 & 12,33 & 55 & 10,15 \\
2012 & 248 & 12,74 & 77 & 14,21 \\
2013 & 231 & 11,87 & 77 & 14,21 \\
2014 & 333 & 17,11 & 76 & 14,02 \\
2015 & 141 & 7,25 & 38 & 7,01 \\
2016 & 252 & 12,95 & 84 & 15,50 \\
2017 & 176 & 9,04 & 51 & 9,41 \\
2018 & 159 & 8,17 & 41 & 7,56 \\
Jumlah & $\mathbf{1 . 9 4 6}$ & $\mathbf{1 0 0}$ & $\mathbf{5 4 2}$ & $\mathbf{1 0 0}$ \\
\hline
\end{tabular}

Sumber: Data primer diolah 2019 